\title{
The Role of Digital Technologies in the New Present and Future of Higher Education
}

\author{
Carles Sigalés
}

Over the last two decades, digitization has transformed the world as we know it. It has changed our economies, industries, leisure, social practices, job markets, politics, and-of course - how we learn. Access to information has continuously been getting faster and more universal. A digital divide still exists but, if the political will is there, we are in a position to take major steps to overcome it.

From an educational point of view, the biggest change stems from the internet and the communication it enables. Digital networks allow content to be brought together, sent and displayed in multimedia formats and using virtual reality to reproduce real world scenes and phenomena, augmenting and enriching them when needed. What is particularly interesting for education is to explore the potential for communication and constant interaction thanks to interconnected devices.

Research consistently highlights the fact that education is a social process, an essential part of this being the interactions between teachers and students, or between the students themselves, as they work together towards collaborative achievements. Today these processes of interaction can take place in traditional classrooms, but they can also take place in digital environments, or sometimes in a combination of both. Face-to-face and online learning are both part of a continuum that offers a wide range of learning ecosystems: almost entirely on-site, blended to varying degrees, or almost entirely online. It is not a question of face-to-face versus online learning; instead, we need to determine which of the many ecosystems possible is best suited to the type of learning we want to provide and the type of students that it is aimed at. There can be more than one valid solution. The choice depends on the purpose.

Throughout history, technological progress has led to major changes in educational practices. As has often been noted, the printing press brought about a great leap forward in how people taught and studied, and undoubtedly represented a huge

C. Sigalés $(\bowtie)$

Universitat Oberta de Catalunya (Open University of Catalonia), UOC, Barcelona, Spain

e-mail: csigales@uoc.edu 
advance for the spread of knowledge. The potential of the technologies available today is enormous, and the changes we can bring about through their use are without precedent. Firstly, because they are of great help in our teaching innovation and improvement processes and in supporting our students' learning. Secondly, and perhaps more importantly, because they let us make education much more accessible to many more people. Nevertheless, teachers' relationships with digital technologies are complex. As some researchers have noted, we tend to approach new technology either with some trepidation or let ourselves be dazzled by it. We generally start by thinking about how this technology can help us improve or extend what we already do without it. And it is only when we get to know it better, and take ownership of it, that we start to think of new uses that had not occurred to us at first. New technologies can also be significant when they can help us achieve ambitious goals that were previously beyond our reach due to a lack of resources or elevated cost. Personalizing education on a large scale, for example, would be unthinkable without the help of digital technologies. The clarity of purpose in what is being taught is what ends up being most important. This does not mean that digital technologies are neutral, no technology is. They affect our lives and, to a certain extent, change them, not always for the better. The giant corporations of the digital era are becoming more powerful than governments and international institutions, selling our data and our privacy, while social media networks can create bubbles of intolerance or use chatbots to spread fake news. One of education's duties is to encourage critical thinking so we can protect ourselves against the misuse of such technology. Despite all this, digital technologies are essential for meeting the enormous challenges facing higher education in the coming decade.

The Universitat Oberta de Catalunya (UOC), the world's first entirely online university, is celebrating its 25th anniversary in 2020. Offering a wide range of bachelors, masters and doctoral degrees, as well as short learning programmes, it has over 70,000 students and many more alumni. Founded as a local online university, today it is a global university with students in more than 130 countries. Over these 25 years of its existence, we have had to be pioneers on many fronts to overcome prejudices favouring a traditional brick-and-mortar education and the stigma associated with distance learning, seen until very recently as a second-rate form of education for second-class citizens.

During this exciting adventure, that of building a new type of university, we have learned, through experience and research, the enormous potential of online learning for the future of higher education. This future has suddenly come much closer as a result of the health, social and economic crisis caused by the COVID-19 pandemic.

The abrupt suspension of face-to-face university lectures in many countries affected by the pandemic has driven an accelerated transition to emergency remote teaching. In this exceptional situation, universities have had to make many changes in a very short time, often without the necessary resources or preparation. The results to date have been very varied. However, given the uncertainty about how long the health crisis will last and its consequences for academic life, it is essential to develop more stable and long-lasting solutions. 
For many universities, the crisis may represent an opportunity to move digitization processes forward and transform their teaching methods for the longer term. But for future scenarios, the measures taken so far to alleviate the current emergency will not be sufficient. The digital transformation of universities has implications at many levels and demands wide-ranging cultural and organizational changes. It must have a real purpose, be shared, supervised and properly planned. If such a transformation is implemented superficially or too hastily, it may end up being frustrating for those carrying it out and counterproductive in terms of meeting its aims.

When considering purpose, we should think of the mission and vision of any given educational institution, its academic goals and the social impact it aims for, and, therefore, the choices it makes regarding its educational model. Higher education has expanded enormously in recent decades and is no longer the preserve of the intellectual and social elites. In some countries, up to $40 \%$ of young people aged between 18 and 25 receive higher education. Much of this growth is driven by new demand linked to the acquisition of high-level professional competencies, which are rooted in interdisciplinary learning.

Working on competencies calls into play information, understanding, skills, values and attitudes, requiring major changes to traditional teaching approaches. Studentfocused teaching and learning methodologies are better for activating knowledgebuilding mechanisms and are key to the development of competencies. The role of teachers remains fundamental in these methodologies but is more focused on guiding, mentoring and the continuous assessment of their students. The transmission of information has ceased to be teachers' main function; the information is now accessible via technology. Teachers can prepare, systematize and deliver it to students so that the time spent with them can be dedicated to more useful tasks: small-group seminars, tutorials, discussions on key subjects, problem-solving, case studies, answering questions, assessments, or other such activities.

The COVID-19 crisis has revealed the weaknesses of teaching methods in some universities. Teaching based on lecturing to large groups - with little interaction with students and limited use of digital media and resources - fell apart, as it did not work beyond the lecture halls. The universities that have adapted best to the closure of classrooms are, naturally, those which have the most developed digital platforms; but they are also those whose students were already more involved in their own learning processes, thanks to the use of more active and participative methods, with better systems of mentoring and assessment. This is the type of method that works best in the virtual environment of online learning. Other methodologies are also viable, but the more they try to imitate face-to-face teaching, the less effective and attractive they become.

Over 25 years, the UOC has experimented with the possibilities and the limits of online education. Today we can be confident in saying that anything that can be done in a traditional classroom can also be done in a virtual learning environment, in equivalent conditions. The vast majority of the services available on a university campus can be provided just as effectively online, so long as they can be digitized: libraries; certain types of laboratory; internships based on simulations or teleworking systems developed in partnership with other institutions and businesses; all the help 
and support services needed for teachers, researchers, students and the transfer of knowledge; spaces for the university community to socialize; guidance services, etc. For the moment, physical presence is still required for some experimental laboratories and internships outside of classrooms, for example, in schools, hospitals and other care facilities. However, constant developments in the use of virtual reality will soon make it possible to provide a significant proportion of these experiences online.

For this reason, the quality standards required of online universities must be as rigorous as those in place for brick-and-mortar universities. In quality assurance processes, some indicators need to be adapted, mainly because of the absence of physical spaces and because of the specific nature of online teaching methods. Nevertheless, the assessment of programme quality, learning outcomes, the effectiveness of learning support systems, and academic teams' teaching and research competencies using the same standards and the same evaluation bodies must be possible.

In recent years, many brick-and-mortar universities have begun to integrate digital technologies into their academic activities. The consequences of the pandemic have accelerated this process, and we can expect that universities will consolidate part of their teaching activities online, albeit conserving their physical campuses, where young people can socialize and experience other facets of university life besides attending classes. However, there are many people for whom the requirement to physically attend a certain number of classes represents an insuperable barrier which prevents them from going to university. These include adults who would have to juggle their studies with work commitments and family or personal responsibilities. For this population, online learning is ideal because of its flexibility and its adaptability to their needs. It is a segment that is increasing due to the growing need for lifelong training. It also includes people who live far from a university and whose circumstances make it impossible to travel or move to live there. Finally, people with disabilities find that online programmes and the use of technology provide them with the support and personalization that they need. Online learning is making a decisive contribution to the inclusion of segments of society which until recently have been underrepresented in university life, due to a lack of opportunities. Online universities now host a wide variety of students. Alongside people who were denied opportunities to study earlier in their lives, we find highly qualified professionals, social leaders, researchers and senior managers who need to regularly update their competencies for their careers to progress. In universities like ours, they find the quality, rigour and flexibility that they need. Technology has enabled us to overcome the limitations of the old distance learning system, putting it on a par with face-to-face teaching. Quality no longer depends on the learning format, but on the talent that the university attracts, how it adapts to meet students' needs and its ability to strive for excellence.

With sustainable development as one of the greatest challenges facing us in the coming decade, universities must also confront major challenges that the immediate future brings. The university must aspire to be a key institution in this new era, as the world's greatest generator of knowledge. Science and research, and the democratization of knowledge, as has been demonstrated during the present crisis, are fundamental to the progress of humanity. Universities must be active in claiming 
their central role in this. And the best way to do this is to understand and adapt to new demands and commit to meeting them.

In recent years, a new type of student has been enrolling in online universities: young people who have the time and resources to attend a brick-and-mortar university but who prefer the flexibility and richness of our methodology and the attractive approach of our programmes. Electronic devices and digital networks empower students, giving them ever greater agency year-on-year. More and more students are rejecting the strictures of traditional classes. Universities do not have a monopoly on knowledge, and they are not capable of meeting the wide variety of modern society's training needs. Students are increasingly accessing knowledge via the internet. They are even using it to listen to their own teachers. Soon it will no longer be possible for universities to maintain the rigid curricula we are used to. They will have to be much more responsive to students' demands and open to personalization. This would be a highly costly process without the support of technology and the advances in artificial intelligence, which is likely to become the teacher's greatest ally in the coming years.

The university will move towards becoming a node in a much wider network, together with other universities, research institutions, knowledge-intensive companies, and public or private institutions. Most of these nodes will be supported by regional and global digital networks. Online universities will be able to reach every corner of the planet where there are people who need to learn and who have an internet connection. Technology will make it possible to offer educational products on a much greater scale, much more sustainably. According to the UNESCO Institute for Statistics, it is estimated that by 2030 there will be 377.4 million students globally enrolled in higher education institutions. This demand, which will be mainly concentrated in emerging economies with rapidly growing populations, can only be met with the support of online learning. Expanding digital networks and providing education and mobile devices to the entire population appears to be more sustainable than growth based exclusively on the construction of new brick-and-mortar campuses, with all the infrastructure that they require. Digital technologies will be key to the goal of delivering universal access to knowledge.

Carles Sigalés is Associate Professor and Vice President for Teaching and Learning at the Open University of Catalonia (UOC). He has been teaching Educational Policies and is also a researcher in the field of online learning and the educational uses of the Internet. He has also been collaborating with the Ministry of Universities and the National Agency for Quality Assessment and Accreditation of Spain (ANECA) in order to promote quality assurance guidelines and criteria for online degrees and master's degrees accreditations. 
Open Access This chapter is licensed under the terms of the Creative Commons Attribution 4.0 International License (http://creativecommons.org/licenses/by/4.0/), which permits use, sharing, adaptation, distribution and reproduction in any medium or format, as long as you give appropriate credit to the original author(s) and the source, provide a link to the Creative Commons license and indicate if changes were made.

The images or other third party material in this chapter are included in the chapter's Creative Commons license, unless indicated otherwise in a credit line to the material. If material is not included in the chapter's Creative Commons license and your intended use is not permitted by statutory regulation or exceeds the permitted use, you will need to obtain permission directly from the copyright holder. 